\title{
E conomía
}

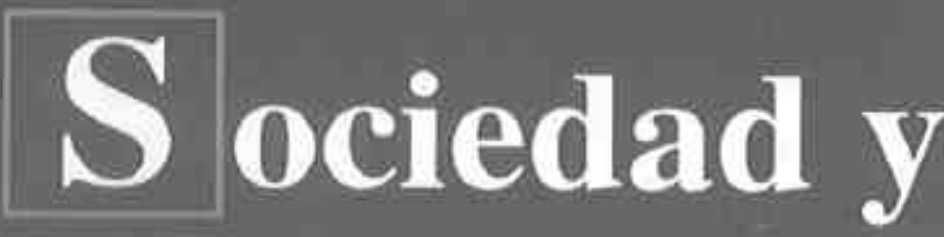

\section{T erritorio}

\section{vol. I, num. 3, enero-junio de 1998}

Profotarización global: Un ucercamiento a la nueva división internucional det trabajo

Pablo Mojfa Reyes y Zeus S: Hernandlo Veteros

Evolución del Producto Interno Hruto de Mexico, 1921-1995: aDeclinacion o histêrests?

Evidencia adicional

Joschin Scarpaci

Ea privatización de las servicios públicos.

La ceperiencia de las ciudades estadounitenses

Adrifin Moreno

Gobierno local, plameación y gestion de servicios públicos en ciudades inedias de Mexiev.

FI chiso de la zona metropolitana de San L.uls Potosi

Jime Sobrino

Blectones municipales en et Estado de Mexico:

un ankilsis del contexto local

Cartos Garrocho:

Lossistemas de infortmacion gerogtifiea en la geografia mediea

\section{El Coleato Mexiquense, A.C.}


Director: Jaime Sobrino

El Colegio Mexiquense, A.C.

Apartado postal 48-D

Toluca 50120, México

Consejo editerial: Francisco Alba El Colegio de México, México José Blanco Universidad Nacional Autónoma de México, México

Boris Graizbord El Colegio de México, México

Soledad Loaeza El Cobgio de México. México

David $\boldsymbol{R}$. Phillips University of Nottingham, Inglaterra

Harry W. Richardson University of Southern California,

Los Angeles, EEUU

Joseph L. Scarpaci Virginia Tech, Blacksburg, EEUU

Martha Schteingart El Colegio de México, México

James Simmons Ryerson Polytechnic University, Toronto,

Canadá

David M. Smith University of London, Londres, Inglaterra

Rodolfo Stavenhagen El Colegio de México, México

Kurt Unger Centro de Investigacióny Docencia Económicas,

México

Peter Ward University of Texas at Austin, Austin, EEUU

En la elaboración de este número participaron Horacio Contreras Colín, y Cynthia Godoy Hernández en la corrección, Luis Alberto Martínez López en el diseño de interiores, y Xiomara Espinoza Velázquez en la formación y composición tipográfica.

La revista no asume responsabilidad por las opiniones expresadas en los textos firmados.

Economía, Sociedad y Territorio es una publicación semestral de El Colegio Mexiquense, A.C. Suscripción anual: en México, 150 pesos. En Estados Unidos y Canadá, individuos, 38 dólares; instituciones, 55 dólares. En Centro y Sudamérica, individuos, 30 dólares; instituciones, 36 dólares. En otros países, individuos $\mathbf{4 6}$ dólares; instituciones, 64 dólares.

Redacción y administración

El Colegio Mexiquense, A.C.

Ex hacienda Santa Cruz de los Patos, Zinacantepec, México

Dirección postal: Apartado postal 48-D, Toluca 50120, México. E-mail: ui @cmq.colmex.mx

D.R.(C) El Colegio Mexiquense, A.C.

Impresoen México-Printed in Mexico Tiraje: 500 ejemplares

Impresión y encuadernación: Jiménez Editores e Impresores. S.A. de C.V., $2^{\circ}$ Callejón de Lago Mayor 53, Col. Anáhuac, 11320 , México, D.F., tel. 52773 40, fax 3994711 .

ISSN en trámite.

Certificados de licitud de título y licitud de contenido en trámite. Autorización del Comité Editorial de la Administración Pública Estatal A: $205 / 4 / 027 / 98$ 

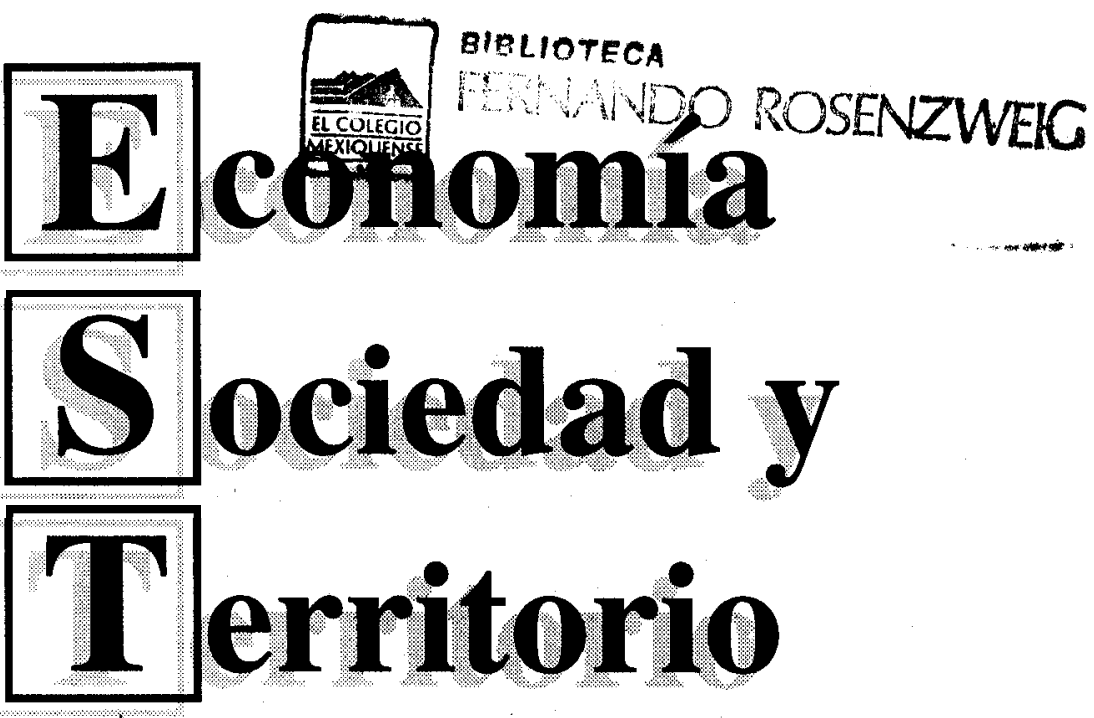

vol..I, núm. 3, enero-junio de 1998

ÍNDICE

David Barkin

Proletarización global: Un acercamiento a la nueva división internacional del trabajo

Pablo Mejía Reyes y Zeus S. Hemández Veleros

Evolución del Producto Interno Bruto de México, 1921.1995:

;Declinación o histéresis?

Evidencia adicional

Josehp Scarpaci

La privatización de los servicios públicos.

La experiencia de las ciudades estadounidenses

Adrián Moreno

Gobierno local, planeación y gestión de servicios públicos

en ciudades medias de México.

El caso de la zona metropolitana de San Luis Potosí

Jaime Sobrino

Elecciones municipales en el Estado de México:

un análisis del contexto local

Carlos Garrocho

Los sistemas de información geográfica en la geografía médica 


\title{
Proletarización global: Un acercamiento a la nueva división internacional del trabajo*
}

\author{
David Barkin \\ Universidad Autónoma \\ Metropolitana-Xochimilco
}

Resumen

En este artículo se analiza el carácter distintivo de la expansión reciente de las relaciones capitalistas de clase para la reproducción de los medios de producción y los bienes requeridos para la reproducción de la sociedad y su sistema prevaleciente de poder. La expansión capitalista procede de acuerdo con las leyes universales de acumulación, pero sus resultados son asombrosamentediferentesen cadasociedad.El manejo competitivo para producir ganancias y acumular continuamente más capital crea fuerzas dinámicas que inducen al cambio tecnológico y a reorganizar la producción y el consumo. La teoría de la internacionalización del capital explica cómo la competencia capitalista y la lucha por mayores ganancias producen profundas transformacionesde la organizaciónsocialy de la producción material, lo cual ha sido observadoen todas las sociedades. Cada sociedad parece imitar los patrones de sus competidores o de sus predecesores, pero los factores naturales, culturalese institucionales, inevitablemente imprimen su huella singular sobre el desarrollo nacional creando un patrón de diversidad dentro de la homogeneidad.

* Traducido del inglés por María de Lourdes Barón L. 
El cambio más significativo en la economía internacional hoy día es la exparsión del proletariado. Con la integración de las naciones individuales al sistema global de producción y distribución para la ganancia, la relación salario-trabajo está extendiéndose hacia nuevos grupossociales y transformandola existencia humana. Los capitalistas emplean trabajadores adicionales para incrementar las ganancias mediante el aprovisionamientode nuevos bienes y servicios, mercancías previamente producidas en el hogar o por medio de arreglos cooperativos dentro de los grupos saciales: ningún aspecto de la vida está exento de este proceso de cosificación. Al mismo tiempo, la difusión internacional de la tecnología y la expansión de los nuevos sistemas estandarizados de producción y distribución, amplifican el efecto que lageneralización delas relaciones capitalistas de producción tiene sobre la vida diaria y la organización social. Aunque todas las sociedades insertas en este mercado mundial están sujetas alas mismas leyes de la acumulación capitalista, las dotaciones específicas de recursos, sus historiasculturales y los conflictosinternos referentes al carácter del cambio económico, están provocandouna diferenciación entre las estructuras nacionales, sociales y productivas.

Por su carácter internacional, a este proceso de expansión capitalista se le denomina internacionalización del capital (IK). ${ }^{1} \mathrm{La}$ expansión ha avanzado durante varios siglos, pero sólo recientemente ha asumido proporciones globales. El capitalismo se expande sobre varios planos simultáneamente: dentro de una sociedad dada, dentro de los grupos sociales de la sociedad, y dentro de los sectores productivos, tanto nacionalcomointernacionalmente. Estaexpansión rara vez toma lugar con un paso uniforme y siempre es profundamente influida por las características específicas de cada escenario. Su interés exclusivo en la producción de cosas para el intercambio (y para Ia ganancia), y el avance aparentemente contradictorio en la multiplicación de mercancías disponibles y la privación material entre grandessectores, haampliadolasdisparidades sociales en el Tercer Mundo, ocasionando transformaciones abruptas de las estructuras sociales, las condiciones productivas y las relaciones políticas.

Estos cambios requieren nuevas formas de entendimiento de la evolución de la economía internacional. En su búsqueda de nuevas

1 Hay una extensa literatura sobre la teoría de la internacionalización del capital. Véanse, por ejemplo, un primer artículo sugestivo de Hymer (1980), los avances del Pallaoix (1975, 977 y 1979) y los desarrollos de Barkin y Rozo (1981) y de Rozo y Barkin (1983). Cada una e estas referencias tiene una guía de la literatura. fuentes de plusvalía y más altas tasas de explotación para acelerar el paso de la acumulación, el capital continuamente intenta expandir el proletariado y extender la producción de bienes. La industrialización en el Tercer Mundo y su redespliegue desde los p̀aíses avanzados es parte de este proceso. ${ }^{2}$ La lucha competitiva entre los capitales intensifica el ritmo del cambio técnico y conduce a la ampliación de las nuevas técnicas de producción y los nuevos bienes en todo el mundo. Aun cuando los capitalistas compitan para ganar mercados copiándose unos a otros, su necesidad de incrementar las tasas de ganancia los obliga a innovar, desarrollando nuevas tecnologías y expandiendo las áreas en las que la producción de bienes invade la actividad y las necesidades humanas.

La teoría que analiza la $\mathrm{m}$ destaca la convergencia de las diversas trayectorias de las economías nacionales. A medida que las relaciones sociales de producción capitalista penetran cada sociedad, la $\mathrm{m}$ transforma a éstas, integrando sus aparatos productivos dentro del mercado global preexistente. Es un proceso dramático de transformación socioeconómica y política que inevitablemente crea sus propios obstáculos para el crecimiento futuro. La misma acumulación de capital está afectada por unacrisis de realización, esto es, por la dificultad de ganar, vendiendo el creciente volumen de bienes creados por la expansión capitalista. Los avances tecnológicos, que por sí mismos son un componente esencial del proceso de expansión, con frecuencia son culpados por estos problemas de la producción y reproducción de plusvalía. Las aspiraciones nacionales de índole política y social también alteran los diseños globales de una clase capitalista actualmente trasnacionalizada por completo. El tradicionalismosocial, la desorganización, o aunla rebelión, imponen compromisos, cambio de ritmo o, llevados al extremo, reorganizaciones de la sociedad que amenazan a la misma organización capitalista de la producción.

${ }^{2}$ Un término usado frecuentemente en Furopa, y especialmente en las publicaciones de la Organización para la Cooperación y el Desarrollo Económico (OCDE), pan describir restructuración pe la industria como un resultado de la expansión del capital protuctivo internacionalmente (Emst, 1980 y 1981); otro término, “deslocalización", tapial productivo especialmente en Francia

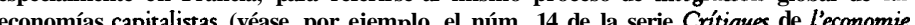
politique, enero-marzo de 1981, titulado "Delocalisation du capital a discipline du travail"). 


\section{La internacionalización del capital}

Elcapitalismoes el sistemadominante de producción de la actualidad. Está caracterizado por un sistema de relaciones sociales en las que un pequeño grupo de personas que controlan los medios de producción, emplean cantidades relativamente grandes de personas para producir los bienes requeridos para su reproducción colectiva. Su meta es acumular capital mediante la producción de ganancias. Para lograrsus objetivos, los capitalistas intentan controlar el aparato del Estado y las instituciones, y los mecanismos para la innovación tecnológica. También se esfuerzan por restructurar las demandas sociales y estructuralesparaque su producción sea más beneficiosa, mientras que el mercado continúa expandiéndose.

Las relaciones sociales de la producción capitalista están caracterizadas por el conflicto.El conflicto constanteentre las diversas clases sociales para llevar adelante sus propios intereses para controlar el producto social, es una característica inherente de la sociedad capitalista. Este conflicto domina la evolución de la producción, condiciona el avance tecnológico e induce a la aparición de nuevos bienes durante el continuo pero desigual proceso de expansión capitalista. En el Tercer Mundo, la lucha frecuentemente opone a los trabajadores que están desarraigados de las formas no-capitalistas de producción (por ejemplo, artesanos y campesinos) contra las burguesías locales reunidas para introducir y acelerar el avance de capitalismo. Irónicamente, mientras el progreso material y técnico conduce a una mayor productividad y eleva la tasa de explotación de trabajo, amenaza con reducir la tasa de ganancia, ocasionando crisis periódicas de acumulación. ${ }^{3}$ Estas crisis siempre imponen fuertes cargos a los trabajadores. Muchos son despedidos y otros sufren decrementos en sus ingresos reales. Con frecuencia esto conduce a una reorganización de la producción, con los productores más poderosos destruyendo a los más débiles.

Históricamente, la expansión capitalista ha reorganizado y extendido la producción a un rango siempre creciente de bienes, debido a la imposición de sus relaciones sociales características. La producción por ganancia circunda a los nuevos grupos, los nuevos sectores de producción y las nuevas regiones. La reorganización de las economías tradicionales arranca el control de la producción de los

${ }^{3}$ La discusión de la crisis mundial del capitaiismo es cada vez más frecuente en la literatura ortodoxa y progresista; dos arálisis diferentes pero mordaces del fenómeno pueden encontrarse en Frank (1980), y en Bowles, Gordon y Weisskopf (1983). campesinos y artesanos que se emplean a sí mismos y los nuevos productos industrializadosdesplazan a los productos hechos en casa; por ejemplo, la sustitución de pan de caja por los productos tradicionales o la contratación de la producción de insumos industriales tales como las legumbres de los campesinos, quienes pierden el control sobre el uso de su propia parcela. En este sentido, la producción no-capitalistaes remplazada por procesos y productos modernos que requieren el engrandecimiento de la fuerza de trabajo asalariada como la base para la expansión futura del capitalismo y su control sobre la sociedad.

El desarrollo de la producción y la acumulación capitalista provocan profundas transformaciones. Estas no se limitan a los países en desarrollo, donde loscambioscualitativosimplican mucho másque una simple reproducción de estructuras económicas traspuestas. Aun en las economías maduras del mundo capitalista, el avance de capitalismo ha dejado una marca dramática. Las dietas e incluso los estilos de vida cambian, y unas regiones son destruidas cuando la producción se mueve de un área a otra, ya sea dentro del mismo país o internacionalmente. El capital continuamente está remodelando la fuerza de trabajo, conforme los trabajadores se organizan para demandar una parte mayor de su producto. Para contrarrestar estos esfuerzos, los capitalistas progresivamente incorporan a los desposeídos y a las mujeres como trabajadores asalariados. Con el incremento del proletariado y los nuevos estilos de vida adquiridos mediante el cambio de los patrones de producción y de consumo, la interacción social y la vida familiar resultan alterados. El capital se insinúa dentro de áreas antiguamente reservadas para el hogar: el cuidado de los hijos es transformado, y la preparación doméstica de la comida y otros servicios del hogar son convenidos en bienes, que deben ser comprados. El resultado es la ampliación de la base para la producción de plusvalía. La resistencia del trabajador y consumidor a los nuevos procesos de trabajo y a la cosificación de la vida diaria toma muchas formas y exige que los capitalistas modifiquen continuamente sus estrategias operacionales para tratar de mantener la rentabilidad.

La viabilidad del capitalismo depende de su habilidad para encontrar nuevas formas de acumular capital para promover su crecimiento posterior. Normalmente, conforme los capitalistas expanden sus mercados para los bienes existentes, amplían el rango de bienes que producen y revolucionan sus técnicas, simplifican el proceso de trabajo y emplean menos trabajadores. La competencia 
obliga a las firmas a expandirse e innovar, así como a emular los últimos avances de los líderes de la industria.

La innovación y la relocalización son mecanismos que responden a la organización del trabajador y a los conflictos sociales en las economías maduras conforme el capital busca nuevoscanales de plusvalía.

La teoría de la $\mathrm{m}$ ofrece un marco para analizar este proceso de crecimiento y sus contradicciones internas. Inicialmente, el capital seexpande internacionalmente en busca de nuevos mercados y nuevos recursos; y finalmente, en busca de nuevas fuentes de trabajadores para emplear en la producción de bienes vendible.' En su expansión internacional, el capital de las economías de capitalismo maduro $s$ ha reunido con los capitales nacionales en otras partes. Esto significa la construcción de nuevos aparatos productivos dedicados a la manufactura de bienes para los mercados mundiales, así como para los mercados locales que emergen en los países en desarrollo. La m es una respuesta a la competencia y al espectro de disminución de las tasas de ganancia. Conduce a la estandarización de la producción y requiere quelos productoresrespondan alas innovaciones deloscompetidores. Al mismo tiempo, provoca la diferenciación de los productos y las técnicas, dado que cada firma trabaja asiduamente para destacar mediante la introducción de nuevos bienes o cambiando los métodos de producción para incrementar su tasa de ganancia.

Uno de los cambios esenciales en el periodo posbélico que ha acelerado la IK, es la consolidación de la empresa trasnacional (ET) como un agenteclaveen la propagacióninternacional de la tecnología, los nuevos bienes, y las nuevas formas de organización de la producción. Es importante resaltar que no es la ET en sí misma la causa de las transformaciones aquí descritas.' La ET, sin embargo, juega un papel importante. La $\mathrm{m}$ ha inducido transformaciones estructurales que están promoviendola articulación de las economías capitalistas nacionales dentro de un sistema coherente pero no unificado. Como resultado, las ET ya no pueden permitirse discriminar contra los países periféricos o dependientes por haber

4 En este sentido, el análisis parte de las presentaciones de la ortodoxia leninista, tomando elementos del análisis de la expansión capitalista de Luxemburgo (1967) para insistir en la importancia fundamental de la internacionalización del capital productivo para completar el ciclo del capital social internacionalizado, más que simplemente analizar el papel del capital financiero y comercial dentro del proceso.

${ }^{5}$ Véase Barnett y Muller, 1974, para una revisión y popularización de una gran literatura de la ET como antagonista principal o incluso como causa de estas transformaciones. llegado después. Ellas necesitan nuevos mercados y deben integrar a nuevos trabajadores a su producción. En consecuencia, deben mover sus operaciones dentro del Tercer Mundo. Pero las ET no pueden simplemente abandonar sus instalaciones y mercados dentro de los países avanzados. En el nuevo orden, la ET se hace más imaginativa al diseñar negocios junto con capitalistas en otras partes del mundopara facilitar su búsqueda de nuevas oportunidades a fin de acumular capital mediante la producción de plusvalía.

La expansión capitalista ha hecho estragos en la división de trabajo heredada, remplazándola con un mosaico de países que producen partes y ensamblan bienes de consumo "mundial". En algunas partes del Tercer Mundo esta producción espera la exportación, ya que la población local es demasiado pobre como para poder comprarla. Ello opera incluso para las minorías domésticas privilegiadas,. puesto que las oportunidades de exportación son limitadas debido a que las mismas industrias están siendoestablecidas en cada país. Pero la industrialización no es la panacea que algunos teóricos han creído: la producciónindustrial requiere importaciones adicionales de bienes intermedios y maquinaria, que inevitablemente conducen a un incremento de la deuda externa para pagar por los bienes necesarios para mantener operando la nueva planta. En consecuencia, noobstante forjarestructuras productivas cada vez más complejas, muchos países del Tercer Mundo deben seguirexportando materias primas y productos agropecuarios para pagar sus importaciones y el servicio de sus deudas. También se encuentran obligados -ignorando las condiciones inciertas del mercado- a ampliar sus programas de industrialización para producir una gama más grande de productos, incluyendo algo de maquinaria y bienes intermedios, en una carrera sin fin para reducir la dependencia del extranjero, y generar divisas adicionales.

La gran complejidad de las economías del Tercer Mundo ocasiona problemas subsecuentes. Conlanuevaproducción industrial y la creciente agricultura comercial desplazando a los productores tradicionales, resultacada vez más común leer acerca de la incapacidad estructural de muchos países para satisfacer sus propias necesidades básicas. ${ }^{6}$ La producción capitalista en el Tercer Mundo rara vez intenta responder a las demandas del trabajador y del campesino,

- Existe una extensa literatura sobre la incapacidad creciente de los paises del Tercer Mundo para satisfacer sus necesidades básicas. Véase la versión de la literatura sobre este tema en: George, 1980, y Moore y Collins, 1977, así como la explicación teórica de este proceso en Barkin, 1982. 
debido a que sus bajos ingresos no representan un mercado dinámico. La divergencia entre producción y necesidades locales se hace patente conforme crece la insuficiencia de la demanda externa y las divisas; conduce primero a un mayor endeudamiento, y luego a una resistencia por parte de la comunidad bancaria de incrementar el financiamiento externo para la producción local. Aun aquellos países en desarrollo que tienen estructuras industriales dinámicas y bajos costos de trabajo - los "éxitos" de la historia reciente-, encuentran que la competencia internacional y las normas de producción los obliga a importar no sólo bienes de capital, sino también alimentos básicos. Consecuentemente, a pesar de los programas deliberados y con frecuencia exitosos para diversificar su producción, ampliar sus mercados internos y expandir las relaciones de producción capitalistas, la mayoría de los países del Tercer Mundo están obligados por sí mismos a volver a las tradicionales exportaciones primarias como una forma de intentar restablecer el balance externo. Empero, la deuda externa de esa región se está convirtiendo en un problema más serio, mientras que los profundos desbalances estructurales polarizan cada vez más a la sociedad.

Estos nuevos programas de desarrollo también exacerban los problemas de empleo. Las transformaciones productivas creadas por la expansión capitalista efectivamente reorganizan a todas las sociedades. Crean presiones que insertan a la gente dentro de la fuerza de trabajo asalariada mediante el desplazamiento de las actividades tradicionales y le obligan a abandonar sus comunidades rurales en busca de nuevo empleo productivo u otras formas de subsistencia. En todos los países en donde esto ha ocurrido, los sectores modernos han sido incapaces de absorber tanto a la gente desplazada de las actividades tradicionales, como a los nuevos integrantes de la fuerza de trabajo. Como resultado, el desempleo abierto y disfrazado, con las dificultades económicas y los conflictos sociales consecuentes, se ha vuelto más grave en los países en desarrollo. Una respuesta a estos desequilibrios estructurales ha sido una fuerte resistencia popular al desplazamiento de la producción de subsistencia y a la destrucción de lasorganizaciones económicas y sociales tradicionales. Loscampesinos y artesanos se han agrupado y unido para construir organizaciones políticas de autodefensa capaces de demandar la asistencia gubernamental para fortalecer su base productiva $\mathbf{u}$ obtener los subsidios necesarios para continuar como grupos sociales y económicos viables. Ellos argumentan que con frecuencia pueden continuar produciendo eficientemente los alimentos básicos y otros productos necesarios para el desarrollo nacional, con recursos (gente y tierra) que de otro modo podrían estar ociosos. Obviamente, el capital se opone fieramente a esta resistencia dentro del Tercer Mundo, debido a que podría reducir su ritmo de acumulación. En general, las iniciativas para promover esta alternativa en los países capitalistas ha fracasado, ya que las piadosas declaraciones de apoyo a la autonomía productiva en los foros internacionales no se materializan en la formulación de una política económica congruente. ' A causa de esta resistencia, el fenómeno de la proletarización global, aludido en el título de este artículo, debe ser entendido simplemente como una tendencia: la meta inalcanzable del capital. Es inalcanzable debido a la incapacidad de éste para ofrecer opciones viables a cientos de millones que no pueden ser empleados productivamente o controlados razonablemente dentro delossectores modernos de nuevas economías.

La IK ha incrementado el volumen del comercio internacional y la complejidad de la distribución global de la producción de bienes. Con la industrialización del Tercer Mundo, la localización de la producción de bienes y de las estructuras productivas ha cambiado. Muchos de los países avanzados se enfrentan a las crisis porque el nuevo crecimiento industrial y la innovación tecnológica ya no pueden compensar los problemas creados por las empresas "que se fugan", ni la caída de la producción de los bienes tradicionales y las serias desarticulaciones regionales y sociales. Por otra parte, en los nuevos países en desarrollo los problemas también se intensifican. A pesar de la acelerada industrialización que produce bienes para nuevos mercados, así como, en algunos casos, para mercados en los países "avanzados", hay endeudamiento y dependencia crecientes en las exportaciones primarias, así como incapacidad para proporcionar empleo productivo a la mayor parte de la población.

${ }^{7}$ Un ejemplo elocuente de esto fue el esfuerzo de poca duración del gobierno mexicano para crear un Sistema Alimentario Mexicano (SAM) de orientación campesina, con el fin de fortalecer su capacidad para producir los alimentos básicos necesarios para la dieta nacional. El experimento se inició debido a que las crecientes importaciones de alimentos básicos estaban convirtiéndose en un drenaje embarazoso sobre el escaso intercambio con el extranjero, mientras que el desempleo campesino y las vastas áreas de tierra ociosa estaban creando un creciente aeitacín social. En la príctica, una parte sustancial de los abuntantes creando una cres a a recursos oficiales asignados al programa fue para los agricultores comerciás más que para los campesinos, y aun las ganancias que se lograron fueron reveridas despues de menos de tres en por h decion de la subecio en la agricultura comecial. Vease Redclift, 1981, y Austin y Esteva, 1987, para una descripción y evaluación de este programa. 


\section{El cambio tecnológico es vehículo de la internacionalización}

La reorganización tecnológica de la producción se ha convertido en una parte central del proceso de acumulación. ${ }^{9} \mathrm{Al}$ igual que ocurre con otros aspectos de la organización social y de la producción material, la actividad científica se ha visto cada vez más sujeta a la lógica de la acumulación de capital. Las decisiones sobre las prioridades, la disponibilidadde recursos, y aun las direcciones de la nueva investigación, parecen estar fuertemente influidas por la búsqueda de medios, para en verdad controlar y simplificar el proceso de trabajo e incrementar su productividad.

La tecnología es particularmente importante para el capital, ya que se orienta directamente a la necesidad de incrementar la rentabilidad. Las innovaciones tecnológicas son útiles para la modificación de las relaciones sociales dentro del lugar de trabajo, dado que promueven un proceso de "descalificación" y reorganización de la fuerza de trabajo en la producción de los bienes de consumo. También animan a la transformación de los bienes de capital - producidos con métodos artesanales -, a su fabricación en masa, por la vía de tomar ventajas de los avances en el diseño auxiliado por la computadora y el control digital. ${ }^{10}$ Los avances tecnológicos en la organización y el control han facilitado la descentralización de la producción e incluso la reintroducción de los sistemas de trabajos realizados en las casas de los mismos obreros. En algunos lugares, los trabajadores autodisciplinados o los pequeños capitalistas organizan sistemas de subcontrataciónque pueden aumentarla productividad y rentabilidad para las ET.

Los trabajadores científicos y técnicos han extendido su influencia de la producción directa al marco de la organización y utilización de la información. Esto significa que las funciones burocráticas y administrativas están siendo racionalizadas para aumentar la productividad del trabajo y la rentabilidad, al mismo tiempo que colaboran con los gerentes para tener un mejor control de

" Esta sección está sustentada en un trabajo previo (Row y Barkin, 1985).

- La reorganización de la producción ha sido una herramienta importante para facilitar el control del capital sobre el trabajo. Véase, por ejemplo, el análisis de Steve Marglin (1974) sobre la transformación de las industrias domésticas en la manufactura por el capital en el sigio XVIII. Braverman (1975) también analiza este proceso en detalle, como lo hacen muchos siglo XVIII. Braverman (1975) también analiza estisis franceses (por ejemplo, Lipietz, 1982).
ana

${ }^{10}$ UNIDO (1981) presenta un extenso análisis de la restructuración global de la industria semiconductora y su impacto en la producción y el trabajo. la firma. Con la interconexión más estrecha de la actividad científica y el proceso de producción, el progreso tecnológico es mejor analizado como una respuesta a las decisiones empresariales competitivas que como un producto autónomo. En sus esfuerzos por producir y redistribuir la plusvalía, la gerencia debe estar interesada en la concepción, generación, adquisición, asimilación, adaptación, el uso y la administración del conocimiento para la reorganización de la producción dentfo de la firma, y la restructuración de la industria nacional e internacionalmente. En consecuencia, conforme la producción capitalista se ha extendido, también lo han hecho los sistemas más avanzados de organización.

La $\mathrm{m}$ se ha intensificado y acelerado por la subordinación de los desarrollostecnológicos y la actividad científica a las normas de la rentabilidad. Con la toma de decisión y el avance tecnológico concentrados en relativamente pocas empresas, la formación de capital productivo casi siempre involucra los últimos avances tecnológicos." Aun cuando se trata de intensificar el uso del trabajo, los capitalistas en los países abundantes en trabajo con frecuencia son incapaces de hacerlo debido a las limitaciones impuestas por la competencia internacional. Los avances tecnológicos han hecho cada vez más factible la subdivisión del proceso de producción, con los componentesproducidosen plantasampliamentedispersasde acuerdo con evaluaciones macroeconómicas hechas por la firma global. Pero, como resultado, los empresarios deben adoptar tecnologías y normas internacionales estandarizadas para asegurar que los componentes puedan ser correcta y velozmente integrados a los productos finales para los cuales están diseñados, así como para contrarrestar la amenaza constante de ser desplazados por los competidores. Aunque algunos productores pueden obtener cierta protección estatal, el mercado transmite estas presiones competitivas incluso a las sociedades más aisladas del mundo capitalista.

La movilidad internacional de los recursos, la transferencia internacional de la tecnología y la expansión global de las relaciones

" La literatura sobre la transferencia tecnológica está repleta de lamentos acerca del impacto de las elecciones tecnológicas inadecuadas sobre el patrón de utilización de lo recursos en el Tercer Mundo: las nuevas tecnologías conducen a procesos de producción intensivos en el uso de la maquinaria y el equipo, mientras que con frecuencia, ellos sustituyen el uso abundante de materias primas para un uso más intensivo del trabajo que les puede conservar. Las tecnologíasestán diseñadas para sustituir capital por trabajo, ya que esto frecuentemente facilita el contrớl del proceso de trabajo y reduce los costos en las sociedades en las que los salarios son altos. Un buen ejemplo de esto se encuentra en Ramesh y Weiss,
1979 . 
sociales de producción capitalista son ahora partes integrales de la estructura social y productiva en todas las naciones del mundo capitalista (influyentes en los países socialistas inclusive). Las firmas oligopólicas se han vuelto más capaces de defender sus intereses y los capitales nacionales en todas partes están siendo obligados a internacionalizarse para sobrevivir. Los intentos nacionales por abrogar o modificar las leyes internacionales de la acumulación del capital, constantemente cambian el ritmo de expansión global, pero una y otra vez estos esfuerzos locales fracasan para alterar el patrón subyacente de expansión con su resultante procesode estandarizacióndiferenciación.

En consecuencia, la IK debe ser entendida como un proceso dinámico de reproducción y crecimiento. Dentro de las partes menos integradas del sistema (sectores, regiones, agrupaciones sociales) el proceso de acumulación capitalista conduce a modificaciones de las estructuras productivas, de las relaciones sociales y de los bienes. Estos cambios son los mismos que están ocurriendo en las partes más maduras del sistema global. Los procesos de acumulaciónlocales están guiados por las leyes generales de produccióny reproducción, aunque cada uno es único debido a que las circunstancias locales sociopolíticas, productivas y técnicas dejan una marca distintiva sobre el manejo universal para la expansión del mercado capitalista y el incremento de la tasa de ganancia. Al mismo tiempo, el proceso de estandarización de las relaciones productivas y sociales, genera una contratendencia hacia la diferenciación dentro del proceso de valorización: incesantemente la competencia obliga a las grandes firmas oligopólicas que ahora dominan a la economía a innovar, mediantelaintroducción de nuevos productos, el desarrollo de nuevas formas para aumentar la productividad del trabajo, y mediante un mejor control de los mercados para insumos o productos.

Sin embargo, se presenta una duda. La $\mathrm{m}$ trabaja para reformar sistemáticamente a la sociedad. Pero este mismo proceso de transformación productiva y social crea fuerzas contrarrestantes. La expansión capitalista es incapaz de absorber productivamente a los trabajadores disponibles y la mayoría de los gobiernos son incapaces y no están dispuestos a financiar los programas de bienestar social necesarios para proporcionar al desempleado y al no empleado un estándar de vida mínimamente aceptable. Como resultado, la meta capitalista de crear un proletariado global se hace cada vez más difícil de alcanzar. En el Tercer Mundo, esto deja una amplia gama de oportunidades disponibles para que la sociedad intente fortalecer sus comunidades y la organización del trabajo tradicionales. Además, como las sociedades requieren más importaciones de las que pueden pagar, acumulan deudas externas que con frecuencia exceden sus posibilidades de pago. Los programas de austeridad impuestos por la comunidad financiera internacional colocan demandas insostenibles sobre las clases trabajadoras y con frecuencia provocan reacciones violentas y respuestas autoritarias. Finalmente, ladivergenciaentre las necesidades sociales y las posibilidades de producción parecen estar creciendo a todo lo largo del Tercer Mundo. Por todas estas razones, la orientación subyacente hacia la $\mathrm{m}$ y la creación de un proletariado global deben ser entendidas como tendencias, como fenómenos sociales que están provocando su propia oposición y que inevitablemente crearán resultados muy distintos en cada país.

\section{La nueva división internacional del trabajo}

La IK ha propagadoel proceso estandarizadode acumulaciónen todas las sociedades capitalistas. La competencia ha conducido al capital no sólo a la búsqueda de nuevos mercados o materias primas, como en el pasado, sino a laincorporación de nuevos grupossociales dentro de un proceso productivo que se desarrolla. ${ }^{12}$ Los bienes manufacturados de consumo, las partes individualesy los productosintermedios, ahora son producidos en todo el mundo capitalista. A pesar de la convergenciade las estructuras productivas, las economías nacionales todavía se diferencian por sus recursos, culturas, clima y tecnología. Los factores institucionales relativos al carácter de la historia y el conflicto social, así como a las alianzas políticasinternacionales y a las estructuras políticas nacionales, también juegan un papel importante en diferenciar a las naciones, aunque la reorganización de la producción y la expansión internacional de la tecnología creen la posibilidad de la producción homogeneizada.

La descripción tradicional de la división internacional del trabajo en términos de las diferencias geográficas en la producción de bienes, ha sido utilizadapara justificar la preservación del conjunto de relaciones de producción entre las clases y las naciones: algunas áreas estaban predestinadas a llegar a ser productoras y avanzadamente industrializadas, mientras que otras estaban condenadas a ser

${ }^{12}$ Sassen-Koob (1982), Wolf (1982), y Portes y Walton (1981), exploran algunos de los efectos de la emergencia de un sistema mundial de trabajo, aunque desde perspectivasteóricas distintas. 
productoras primarias. ${ }^{13} \mathrm{La}$ teoría reflejaba la distribución del poder prevaleciente, justificando la "optimación" de la situación mediante la argumentación de que ésta conduciría a costos más bajos para todos los participantes en un sistema mundial caracterizado por el libre comercio y la movilidad del capital.

En este escenario, los productores primarios participaban en el comercio mundial como socios dominados. En muchos casos, los bienes que ellos exportaban no eran producidos dentro de relaciones capitalistas de producción y sus relaciones internacionales eran periféricas. Parte de la producción y circulación respondió a las demandas y a la lógica del mundo capitalista, aunque las mismas sociedades no eran capitalistas. De hecho, toda la estructura de relaciones económicas internacionales fue tangencial a la coherencia interna y a la dinámica de la acumulación capitalista. El comercio internacional fue, de hecho, el intercambio de bienes entre los países cuyas economías no estaban articuladas, donde el desarrollo capitalista y los movimientos cíclicos de una región no determinaban únicamente lo que estaba pasando en todas partes. Las teorías anteriores del comercio mundial, entonces, reflejan correctamente la naturaleza desarticulada de las relaciones económicas internacionales de los siglos pasados. Pero fueron incapaces de identificar el impacto que la expansión capitalista en el siglo XX estaba teniendo sobre el Tercer Mundo, un impacto que finalmente iba a forjar el sistema capitalista mundial que ahora domina las relaciones económicas internacionales.

A principio de siglo, el capital internacional ya había empezado a invertir en la nueva producción industrial en los países "sureños". Algunas fracciones de las tradicionales burguesías terratenientes nacionales se adaptaron a las nuevas oportunidades, uniéndose con otros grupos para formar una élite capitalista dinámica. Estoscapitalistas rápidamente descubrieron las limitadas posibilidades de una acumulación posterior proveniente de la producción primaria de exportación. Los comerciantes expandieron ésta hacia áreas no capitalistas y desataron una feroz competencia que deprimió los precios en los mercados mundiales. Además, las ganancias de este

${ }^{1}$ El contenido normativo de la teoría neoclásica se basa en los escritos clásicos de Heckscher (1919) y Ohlin (1935), fundamentados en la teoría de las ventajas comparativas determinadas por las proporciones de los factores productivos en cada país. Esta escuela insiste en que la especialización basada en la disponibilidad de factores conduce a una distribución global óptima de la actividad económica, haciendo caso omiso de las violaciones de patentes de los supuestos del modelo subyacente. Para una discusión y una evaluación on

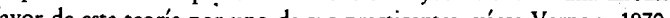

comercio no fueron reinvertidas para expandir la fuerza de trabajo asalariada en otras actividades.

Los nuevos industriales comenzaron a desplazar a los comerciantes. Ellos reorganizaron las economías nacionales y las políticas estatales para facilitar y acelerar sus planes de acumulación. Los patrones que emergieron en cada área dependieron de las condiciones locales: en América Latina la industrialización de sustitución de importaciones posiblemente fue resultado de que las exportaciones primarias pudieron ser utilizadas para pagar por el equipo de capital y los bienes intermedios importados necesarios; las operaciones de ensamblaje de exportación proliferaban en el este de Asia, donde las materias primas no existían (Singapur, Hong Kong), o donde la producción no estaba organizada para los mercados mundiales (Taiwan, Corea del Sur). Cualquiera que fuese el camino elegido, el resultado subyacente fue similar en cualquier lugar: 1) la transformación de una parte importante de la fuerza de trabajo en proletariado; 2) una explosión demográfica que se combinó con una ola de migración rural-urbana para crear grandes ciudades; 3) un descuido sistemático de la producción de comida doméstica debido a que la producción de alimentos y productos industriales de exportación se requería para pagar por las expansivas necesidades de importación; y 4) un programa de inversión incapaz de crear suficientes empleos para los nuevos integrantes de la fuerza de trabajo, y mucho menos de absorber a los millones desplazados de las organizaciones sociales y de las actividades económicas tradicionales. El dešarrollo capitalista reorganizó a la sociedad, tratando de separar a los productores directos de su propiedad y de sus herramientas.

Con el acelerado ritmo de innovación tecnológica característica del cuarto de siglo pasado, otros cambios todavía estaban por venir. Las grandes empresas diversificaron las estructuras industriales en los cincuenta, y redescubrieron la inversión extranjera como una forma efectiva de elevar sus ganancias. No fue suficiente crear nuevos productos y expandir los mercados. La competencia forzó a que los gigantes desplazaran o absorbieran a los productores existentes. El imperativo corporativo para producir mayores ganancias y continuar creciendo, provocó un flujo internacional de capital que comenzó como una invasión estadounidense en Europa, ${ }^{14}$ que pronto se expandió para inundar al Tercer Mundo. Estas nuevas 
inversiones transformaron la organización de la producción en todas partes del orbe.

Conforme se recuperaron de los efectos devastadores de la Segunda Guerra Mundial, los capitalistas europeos y luego los japoneses, enfrentaron exitosamente el liderazgo americano de la economíamundial. Todos encontraron benéfico el establecimiento de subsidiarias y sucursales en el extranjero, mientras que muchos también emprendieron negocios unidos con los capitalistas locales. Éstos fueron capaces de tomar ventaja de los mercados locales y de los incentivos ofrecidos por los países en desarrollo, ansiosos por atraer nuevas inversiones. Con la rápida declinación en los costos de transporte y comunicación y la generalización de una red de aerolíneas internacionales, la dispersión geográfica de la producción se convirtió en lugar común. Cualquier problema o costo en que pudiera incurrirse era superado por los beneficios ofrecidos por el acceso privilegiado a las materias primas y a los nuevos mercados, así como por una fuerza de trabajo barata.

Aunque muchos países del Tercer Mundo continuaron exportando materias primas básicas y otros productos primarios, también comenzaron a exportar productos industriales. Las firmas internacionales usaron los insumos domésticos y los componentes importados como parte de un patrón de una "localización global" de producción y distribución. Sin embargo, la industrializaciónno sólo significó producción para la exportación, ya que en la mayoría de los países de nueva industrialización (NIC, por sus siglas en inglés) las burguesías se unían con parte del proletariado y los sectores medios para forjar nuevos mercados para los bienes duraderos y los no durables procesados. La demanda para la protección tarifaria se convirtió en una forma de lucha conjunta por nuevos trabajos y mayor ganancia.

El comercio en la agricultura se hizo cada vez más complejo conforme algunos grupos agrícolas demandaban y recibían protección y subsidios(especialmenteen el Mercado Común Europeo), mientras que otros presionaban en favor de las importaciones crecientes provenientes del Tercer Mundo. Las importaciones podrían ayudar a bajar el costo de la vida, a reducir el valor de la fuerza de trabajo como manera de incrementar las ganancias. Ellos también pudieron ampliar los mercados de ultramar, mediante la protección de las frágiles economías de las naciones exportadoras que de otro modo no podrían pagar por las importaciones industriales o el servicio de sus deudas externas, cada vez más inrnanejables.
Esta es la compleja situación que ha incitado a una nueva literatura: la discusión de la nueva división internacional de trabajo..$^{15}$ Para quienes examinan el comercio y la especialización internacionales en términos de flujos específicos de bienes y su localización, es claro que la composición y el volumen del comercio internacional han sido dramáticamente alterados. ${ }^{16}$ Para otros los cambios son más difíciles de caracterizar, ya que una parte sustancial del comercio internacional de partes manufacturadas y productos terminados debe ser revaluada debido a que sólo es un intercambio de productos dentro de una sola ET ${ }^{17}$ La creciente literatura sobre la nueva división internacional del trabajo es parte del esfuerzo ampliamente difundido por entender la naturaleza cambiante de las relaciones Norte-Sur. ${ }^{18}$

El nuevo patrón del comercio internacional ha provocado el proteccionismo creciente en los países industrializadosque amenaza seriamente la viabilidad de los programas de modernización en muchos países de reciente idustrializacións (NIC). Los conflictos se originan debido a que las nuevas estructuras industriales son muy similares a los segmentos modernos de los sectores ya atrincherados firmemente en los países avanzados como un resultado del proceso de estandarización-diferenciación discutido en la sección anterior. El cambio de frente industrial está transfiriendo las industrias de bienes de consumo a los NIC, desplazando las operaciones más costosas a las economías maduras. Además, los nuevos productos de consumo y mercados del Tercer Mundo con frecuencia son simples copias de las contrapartes existentes en todas partes. En consecuencia, el desarrollo del Tercer Mundo, como está sucediendo actualmente, no necesariamente ofrece una nueva gama de productos al comercio mundial, sino una nueva ubicación de la producción de los bienes

15 Actualmente numerosos grupos tienen programas para estudiar la cambiante organización de la economía mundial. Por ejemplo, la Intemational Labor Office tiene una oficina especial que examina los problemas de la nueva división internacional del trabajo, mientras que otras instituciones examinan el fenómeno como parte de sus estudios del nuevo orden económico internacional.

${ }^{16}$ Cf. Frobel, Henrichs y Kreye, 1979

${ }^{17}$ Cf. Helleiner, 1979, y Grubel y Lloyd, 1975.

${ }^{18}$ La conferencia sobre "Internacionalización de capital e industrialización en la periferia" patrocinada por el Centro de Investigación y Docencia Económicas (CDE) (Minian, 1983 y patrocinada por el Centro de Investigación y Docencia Económicas (CDE) (Minian, 1983 y
1984) es un ejemplo de las numerosas conferencias patrocinadas por grupos nacionales e 1984) es un ejemplo de las numerosas conferencias patrocinadas por grupos
internacionales sobre el asunto de la nueva división internacional del trabajo. 
existentes, con nuevos mercados y un proletariado internacional vastamente difundido.

La economía mundial está caracterizada ahora por una escala de acumulación de capital mayor y geográficamente extendida, más que por nuevos productos. Los profundos cambios en la forma en que la producción está organizada, su impacto sobre la fuerza de trabajo, y la consecuente restructuración de las relaciones sociales y políticas dentro de cada país, son determinantes mucho más importantes de la naturaleza cambiante de las relaciones económicas internacionales que los cambios en el comercio de los bienes." La nueva división internacional del trabajo, entonces, no es simplemente una relocalización de la producción de bienes; es una restructuración global de la fuerza de trabajo para incluir nuevos segmentos sustanciales de población. Su integración necesariamente ampliarálos mercados locales, cambiará los patrones de interacción social, y alterará las estructuras productivas. Este será el caso no solamente del Tercer Mundo, sino de toda región, como resultado de los ajustes que también ocurren en las economías maduras.

Quizá el cambio más notable en la producción es la declinación de la autosuficiencia alimentaria entre los paísesdel Tercer Mundo. La incapacidad de muchos países a todo lo largo del mundo para alimentarse a sí mismos es un fenómeno nuevo. Históricamente, se ha producido la comida para respondera las necesidades regionales: los costos de transporte y los desperdicios fueron bastante altos para la sociedad, como para depender de las importaciones regionales o nacionales y satisfacer las necesidades biológicas básicas diarias de su población. Esta situación prevaleció por largo tiempo, aun en el presente siglo. Con la expansión de las nuevas relaciones de producción, la reorganización de la fuerza de trabajo, y la incorporación de la agricultura al circuito del capital social, un país tras otro se han encontrado cada vez con más dificultades para

${ }^{19}$ Esta aproximaciónno comienza con los patrones prevalecientes del comercio de bienes debido a que ellos mismos continuarán cambiando rápidamente como resultado de los avances ecido ten paises más ricos, y los precios relativos de las materias primas basicas y los insumos de produccion. Las allanzas polteas entre los Nic en otros paises del Tercer Mundo y lo acuerdos con los miembros del antiguo bloque socialista, asi como los programasde austeridad impuestospor los poderes capitalistasdominantes, tambiênafectarán profindamentelos flujos véase Fajnzylber, 1983 producir los alimentos necesarios para la mayor parte de su población. ${ }^{20}$ Es evidente que la transferencia de recursos de producción y el trabajo mismo de la producción de alimentos básicos a la producción suntuaria y no comestible para los mercados local o de exportación, han creado sistemáticamente problemas de autosuficienciaalimentariaen todoel Tercer Mundo. Losmecanismos del mercado que impulsan un retiro de los recursos agrícolas del consumo básico también crearon una situación similar en otros sectores productivos, con el resultado paradójico de que muchos de estos países que se han industrializadomás rápidamente san los menos capaces de satisfacer las necesidades básicas de su población. Incluso cuando grandes segmentos del campesinado no han sido integrados al proletariado, la política estatal sistemáticamente discrimina contra la producción de alimentos básicosexacerbandoalgunos de los conflictos sociales que crea la IK.

Estos complejos cambios en las relaciones y estructuras nacionales de producción son la base para sugerir que la nueva división internacional del trabajo sea correctamente analizada como el proceso de incorporación de los nuevos gruposdentro de una fuerza de trabajo progresivamente internacionalizada. Lostrabajadoresestán crecientemente sujetos a un conjunto similar de relaciones de producción, mientras que los mismos patrones de acumulación de capital difieren enormemente de una sociedad a otra (por las razones anteriormente discutidas). Como nuestro interés principal es el entendimiento de las fuerzas subyacentes que influyenen la evolución de la acumulación de capital en la sociedad de hoy, resulta crucial el hecho de enfocar los mecanismos para la expansión del capitalismo y la integración de un sistema de producción y un mercado capitalistas.

\section{El impacto del nuevo sistema global en la vida diaria}

La dramática transformación de las relaciones económicas internacionales desde la Segunda Guerra Mundial es el resultado de una expansión sin precedentes de la producción capitalista, que se revolucionósistemáticamentemediante lacreaciónde unproletariado y la multiplicación de las fuerzas productivas. La mera distribución internacional de la producción no puede explicarse simplemente mediantela restructuración del comercio mundialo por las demandas

20 Para un análisis de las razones para la declinación de la autosuficiencia alimentaria, véanse Perelman, 1977; Rozo y Barkin, 1983; y Barkin y Suárez, 1985. 
de importación de materias primas, componentes y productos terminados por los países centrales. La expansión de las inversiones productivas en el Tercer Mundo y la integración mundial de los procesos de producción han transformado profundamente la forma en que los bienes son producidos. La teoría de la IK se enfoca al avance de la acumulación de capital y al ritmo del cambio tecnológico. Éstos conducen a la recomposición de la producción, así como a la sujeción de una proporción siempre creciente de la población mundial a la conflictiva relación proletaria.

En el sistema global capitalista la producción altera los estilos de vida y los patrones de consumo conforme las sociedades se ajustan a la nueva organización de la producción. Los viejos productos son desplazados por los nuevos bienes, más adecuados alos requerimientos de la acumulación. Los mercados mayores todavía se localizan en los países capitalistas avanzados, no por sus grandes poblaciones, sino por su alto poder de compra. Pero aun en muchos de los NIC, las nuevas demandas de consumo crecieron rápidamente conforme la industrialización creó un nuevo proletariado junto con un dinámico sector medio. Esta expansión fomenta la extensión de nuevos patrones de consumo para complementar el nuevo conjunto de relaciones sociales impuesto por la generalización del trabajo asalariado dentro de la producción.

La expansión de los nuevos estilos de consumo no se ha limitado al Tercer Mundo. La exposición capitalista ha puesto su marca en una gama creciente de actividades domésticas que previamente no se proporcionaban como servicios corporativos. Por ejemplo, en las décadas recientes hemos presenciado el crecimiento de la industria de alimentos como un área principal de inversión capitalista, no, sólo en cuanto a su procesamiento para el consumo doméstico (que ha crecido extraordinariamente), sino también en la reorganización de la preparación y comercialización de la comida fuera de casa. El servicio de restaurantes ha sido restructurado conforme el capital entra sistemáticamente al campo, ofreciendo comidas estandarizadas rápidas y sustancialmente menos caras que las de los restaurantes tradicionales. Estos establecimientos operan no simplemente para retomar una ganancia que permita a los capitalistas individuales vivir (como tantas veces es el caso de la organización de la producción de la pequeña burguesía), sino preferentemente para contribuir a la continua multiplicación y expansión de las actividades productivas, que son la piedra angular de la acumulación capitalista. La misma industria procesadora de alimentos ha cambiado conforme encuentra formas de ampliar sus mercados e incrementar su productividad. El cambio técnico y el uso efectivo de la propaganda han hecho rentable la descomposición de alimentos naturales y su reconstitución para una vida útil más larga y una preparación más rápida. Estas tendencias no han estado restringidas a las dietas "occidentales" tradicionales, sino que también se han extendido para incorporar nuevos tipos de alimentos o estilos de cocina del Tercer Mundo al patrón global de transformación capitalista (en un diseño particularmente capitalista que frecuentemente hace que el nuevo producto se parezca sólo vagamente al original que lo inspiró). Los restaurantes mexicanos, los de comida cantonesa y de especialidades griegas (entre otras), ahora diversifican el menú disponible a partir de las cadenas de hamburguesas, pollo, langosta y pizzas, iniciadas en los Estados Unidos pero en expansión hacia todos los mercados potenciales. La internacionalización de los alimentos y de las variedades de los restaurantes no requiere que cada establecimiento o la misma cadena sea propiedad de un capitalista internacional, sino que el concepto de servicio de comida sea concebido ahora como una parte de un proceso mayor de acumulación de capital en el que los alimentos son preparados por trabajadores asalariados, organizados para producir una ganancia con una alta rotación de capital. El restaurante individual propiedad de un empresario aislado trabajando solamente para producir su propio sustento, parece estar convirtiéndose en un fenómeno en extinción en la sociedad capitalista.

El servicio de comida es un ejemplo particularmente vívido - pero no aislado- de la forma en que la IK está alterando la vida diaria en los países avanzados y pobres de la misma manera. Los servicios domésticos de cualquier tipo están siendo modificados conforme los comerciantes locales confrontan a las organizaciones nacionales o trasnacionales, tratando de desplazarlas o absorberlas. Ejemplos de la reorganización y cosificación de la vida para llenar las necesidades de valorización abundan, como en el caso del comercio al menudeo en supermercados o en boutiques, servicios veterinarios para mascotas, mantenimiento y reparación de aparatos domésticos, cuidado de los niños y atención médica, que han sido alterados sustancialmente conforme la organización capitalista se ha expandido para incluirlos.

La IK no se limita a estos productos finales. Hay ejemplos de la forma en que la expansión capitalista ha alterado directamente la organización de la vida diaria. Pero los cambios que estamos considerando enmarcan virtualmente cada aspecto de la existencia humana en el mundo capitalista. Aunque las modificaciones de los estilos de vida son mucho más profundas y quizá más inquietantes en 
el Tercer Mundo, tal vez están mejor documentadas en países avanzados; la proletarización de la fuerza de trabajo se ha acelerado en las partes más pobres del mundo: los capitalistas suelen trasplantar simplemente los patrones establecidos para aumentar la producción, sin considerar su impacto potencial en la sociedad o el ambiente. Como resultado, las incongruencias entre la producción material y la organización social están proliferando. En los países avanzados, esa proletarización ha procedido por siglos. Pero ahora los capitalistas están buscandoactivamente grupos inicialmente marginales, tomando ventaja de las disparidades internacionales para reclutar inmigrantes dentro de los países avanzados. Esto es parte de su lucha constante por limitar el crecimiento de los salarios reales, y disciplinar a la fuerza de trabajo mediante la amenaza de su despido. En otras partes del mundo las nuevas relaciones sociales de producción capitalista han tenido efectos todavía más dramáticos. La transformación de los trabajadores en asalariados ha incorporado a muchos campesinos a la forma industrialy a otras formas de trabajo urbano, y ha reorganizadoel día laboral y la misma sociedad. La literatura sobre este tema es muy amplia y bien conocida, de modo que aquí no se requiere un sumario. $^{21}$

El cambio en las relaciones sociales es un resultado de la expansión de la base productiva. Las nuevas oportunidadesde obtener ganancias surgieron de exigencias nacionalistas que cubrieran los mercados domésticos con la producción local, aun cuando estaba controlada por extranjeros. Las ET crearon y usaron tecnología para forjar nuevas oportunidades para ellas mismas como economías nacionales desarrolladas. Reorganizaron sus estructuras productivas para aprovecharse de las exenciones de impuestos, una disciplinada y barata $\rightarrow$ si bien poco adiestrada - fuerza de trabajo, y subsidios financieros ofrecidos por las autoridades de los países más pobres y en las regiones deprimidas dentro de los países más ricos. Las industrias de bienes de consumo dieron un salto hacia arriba en respuesta a los planes.de la industrialización para satisfacer a los mercados locales a través de todo el mundo en desarrollo. Los capitalistas locales se unieron a sus contrapartes internacionales al usar los ahorros internos y los fondos internacionales para construir nuevas plantas y reclutar nuevos trabajadores con el fin de tomar ventaja de los atractivos incentivos financieros. En otras ocasiones, las ET, directamente o por medio de los capitalistas locales, organizaron la producción de

${ }^{21}$ Portes y Walton (1981) presentan una revisión de este material.

componentes o las operaciones de ensamblaje para sus mercados mundiales.

Estos cambios en los bienes y la localización de la producción han producido una reorganización de las relaciones económicas internacionales. Las actividades técnicas y científicas están avanzando en respuesta a las demandas de la rentabilidad capitalista para facilitar la restructuración de la producción. Las operaciones de ensamblaje y la manufactura de componentes ahora son una parte importante y creciente de la economía mundial, ya que los controles técnicos y el nuevo equipo permiten una mayor calidad para los productos estandarizados producidos internacionalmente. Con la descomposición de la producción emergen nuevas industrias a medida que se diseñan bienes para ser ensamblados a partir de componentes producidos en diversas plantas. La búsqueda global proporciona una alternativa, y amenaza la viabilidad de fábricas integradas donde los conflictos laborales y la política nacional o los disturbioseconómicos podrían desanimar la planeación corporativa internacional.

Laexpansión capitalistatambiénestá estimulandolaaparición de nuevos productos de consumo internacionalizado en el Tercer Mundo. Aunque los nuevos bienes están siendo producidos localmente por el nuevo proletariado, los sectores medios y las élites frecuentemente crean sus propios cuellos de botella. La producción doméstica impone una estricta dependencia en las importaciones. Ahora la producción y el empleo, no sólo las normas de consumo de la burguesía, dependen directamente de la disponibilidad de materias primas, bienes intermedios y equipo importados. En consecuencia, conforme el intercambio con el extranjero se vuelve escaso, debido a la carga creciente de los pagos de la deuda, a la dificultad cada vez mayor para encontrar mercados de exportación, y por la aparentemente inevitable necesidad de aumentar lasimportacionesde bienes de consumo básico, la nueva capacidad productiva se ve amenazada con la ociosidad.Pero el nuevo proletariadono disfrutalos beneficios de un sistema de seguridad social o seguro de desempleo para amortiguar los efectos, a diferencia de lo que ocurre con los trabajadores de los países más ricos.

Finalmente, la reorganización de las economías nacionales provocada por la m está produciendodesplazamientossustanciales de la producción tradicional. Las producciones campesina y artesanal ceden al trabajo hecho en casa bajo las órdenes de las empresas capitalistas y la moderna empresa agrícola. Las demandas conflictivas para subsidios oficiales y una base impositiva limitada frecuentemente distorsionan la estructura productiva posteriormente, conforme los 
subsidios se canalizan a los programas de industrialización y sostén de las exportaciones, beneficiando a una pequeña clase capitalista nacional y respondiendo a las presiones financieras de la comunidad financiera internacional. Aparentemente la víctima universal de estas presiones sobre el presupuestonacional es la producción doméstica de productos alimentarios básicos y otros bienes esenciales para el consumo en masa. Los alimentos y otros productos básicos deben ser importados y distribuidos, así sea a precios altos con sustanciales subsidios del gobierno; en cualquier caso, ocasionando una inflación con serias consecuencias para los estándares de vida de las masas. La internacionalizacióndel capital, en consecuencia, produceel resultado paradójico de incrementar el potencial productivo de la sociedad, al mismo tiempo que empobrece a su gente.

\section{Bibliografía}

Austin, James y Gustavo Esteva (eds.) (1987), The Mexican Food System, Ithaca, Nueva York, Cornell University Press.

Barkin, David (1982), "The Impact of Agribusiness on Rural Development", en S. Mc Nall (ed.), Current Perspectives in Social Theory, vol. 3, Greenwich, Conn., JAL Press.

- y Carlos Rozo (1981), "L'agriculture et l'internationalization du capital", Revue Tiers.Monde, núm. 88, octubrediciembre, pp. $723-745$.

y Blanca Suárez (1985), El finde la autosuficienciaalimentaria, México, Centro de Ecodesarrollo-Ed. Océano.

Barnett, Richard y Ronald Muller (1974), Global Reach: The Power of the Multinational Corporation, Nueva York, Simon and Schuster.

Bowles, Samuel, David Gordon y Thomas Weisskopf (1983), Beyond the Wasteland, Nueva York, Anchor.

Braverman, Harry (1975), Trabajo y capital monopolista, México, Nuestro Tiempo.
Ernst, Dieter (ed.) (1980), The New International Division of Labour Technology and Underdevelopment, Consequencesfor the Third World, Frankfurt y Nueva York, Campus, Verlag.

(1981), "Special issue on industrial redeployment and international transfer of technology: Trends and policy issues", Viertel Jahres Beginne, núm. 83, marzo.

Fajnzylber, Fernando (1983), La industrialización trunca en América Latina, México, Nueva Imagen.

Frank, Andre Gunder (1980), Crisis in the World Economy, Nueva York, Holmes and Meier.

Frobel, Folker, Jurgen Henrichs y Otto Kreye (1979), La nueva división internacional del trabajo, México, Siglo XXI.

George, Susan (1980), Cómo muere la otra mitad del mundo: las verdaderas razones del hambre, México, Siglo XXI.

Grubel, Herbert y Peter Lloyd (eds.) (1975), Intra-Industry Trade, Londres, Macmillan.

Heckscher, Eli (1919), "The effects of foreign trade on the distribution of income", en H. S. Eris y L. A. Metzler, (eds.), Readings in the Theory of Internationul Trade, Filadelfia, Blakiston, 1950.

Helleiner, Gerald K. (1979), "Transnational corporations and trade structure: The role of intra-firm trade", en H. Giersch (ed.), On the Economics of Intra-Industry Trade, Tubingen, JCB Mohr.

Hymer, Stephen (1980), The Multinational Corporation, Cambridge y Nueva York, Cambridge University Press.

Lipietz, Alain (1982), "Marx or Rostow?", New Left Review, núm. 132, marzo.

Luxemburgo, Rosa (1967), La acumulación del capital, México, Grijalbo. 
Marglin, Steve (1974), "What do bosses do? The origin and function of hierarchy in capitalist production", Review of Radical Political Economics, vol.6, núm. 3, verano, pp.60-112.

Minian, Issac (ed.) (1983 y 1984), Transnacionalización y periferia semindustrializada, I y II, México, CIDE.

Moore, Lappe y Francis Collins (1977), Comer es primero, México, Siglo XXI.

Ohlin, Bertel (1935), Interregional Trade and International Trade, Cambridge, Harvard University Press.

Pallaoix, Christian (1975), Las firmas multinacionales y el proceso de internacionalización, Madrid, Siglo XXI.

\section{(1977), La internacionalización del capital, Barcelona, Blume.}

(1979), Proceso de producción y crisisdel capitalismo, Barcelona, Blume.

Perelman, Michael (1977), Farming for Profilts in a Hungry World: Capital and the Crisis in Agriculture, Montclair, Nueva York, Osmun.

Portes, Alejandro y John Walton (1981), Labor, Class and the International System, Nueva York, Academic Press.

Ramesh, J. y Charles Weiss (1979), Mobilizing Technology for World Development, Nueva York, Praeger and Overseas Development Corporation.

Redclift, Michael (1981), "Development policymaking in Mexico: The Sistema Alimentario Mexicano", Working Papers in UsMexican Studies, núm. 24, San Diego.

Rozo, Carlos y David Barkin (1983), "La producción de alimentos en el proceso de internacionalización del capital”, El Trimestre Económico, vol. L(3), núm. 199, junio-septiembre, pp. 16031626.
(1985), "La tecnología y la acumulación", Investigación Económica, núm. 173, pp. 191-213

Sassen-Koob, Saskia (1982), "Recomposition and peripherialization at the core", Contemporary Marxism, núm. 5, verano, pp. 88100

Servan-Schreiber, Jacques-Jean (1968), El desafío americano, Santiago de Chile, Zig-Zag.

UNIDO (1981), "Restructuring world industry in a period of crisis, The role of innovation: An analysis of recent developments in the semiconductor industry", Documento, UNIDO/IS-285.

Vernon, Raymond (1970), The Technology Factor in International Trade, Nueva York, Columbia University Press para el National Bureau of Economic Research.

Wolf, Eric (1982), Europe and the People Without History, Los Angeles, University of California Press. 